\title{
Large Giant Cell Arteritis with Eye Involvement
}

\author{
Jianu Dragoş Cătălin²,2, Jianu Silviana Nina³, \\ Petrica Ligia ${ }^{1,4}$ and Şerpe Mircea ${ }^{2}$ \\ 1"Victor Babeş" University of Medicine and Pharmacy, Timişoara \\ ${ }^{2}$ County Emergency Hospital, Department of Neurology, Timişoara \\ ${ }^{3}$ Military Emergency Hospital, Department of Ophthalmology, Timişoara \\ ${ }^{4}$ County Emergency Hospital, Department of Internal Medicine, Timişoara
}

Romania

\section{Introduction}

Giant cell arteritis (GCA), also called Horton, temporal, or granulomatous arteritis, is a primary vasculitis that affects extracranial medium (especially branches of the external carotid artery) and large-sized arteries (aorta and its major branches) (Levine\&Hellmann, 2002). The diagnosis of GCA requires age more than 50 years at disease onset, new headache in the temporal area, temporal artery tenderness, and/or reduced pulse, jaw claudication, systemic symptoms, erythrocyte sedimentation rate (ESR) exceeding $50 \mathrm{~mm} / \mathrm{hr}$, and typical histologic findings (granulomatous involvement) in temporal artery biopsy (Hunder et al., 1990). Approximately $40-50 \%$ of these patients have ophthalmologic complications, consisting of visual loss secondary to arteritic anterior ischemic optic neuropathy (AION), or central retinal artery occlusion (CRAO), homonymous hemianopsia or cortical blindness (unilateral or bilateral occipital infarction) (Gonzales-Gay, 2005).

\section{Epidemiology}

Over the last 25-30 years, GCA has been found to be the most common type of vasculitis in Europe and North America. Incidence of GCA is higher in white individuals than those of other ethnicities. The highest incidence rates are reported in Scandinavian countries and North American populations of the same descent. In these regions, the annual incidence rates are generally higher than $17 / 100,000$ people per population age $>50$ years (Salvarani et al., 1995). The incidence of GCA is lower than $12 / 100,000$ people per population age $>50$ years in Southern European and Mediterranean countries.

The incidence increases with age and peaks in the 70-79 years age group: 100,000 people per population age $>50$ years.

In Northern European countries, women are affected more frequently than men (3:1 to 5:1). A lower ratio of women to men was observed in Southern Europe and Israel (Salvarani et al., 1991).

As the population throughout the world continues to age, an increased prevalence of disease should be expected. 
Higher physician awareness was proposed as being responsible for the progressive increase of GCA reported in different parts of the world (Gonzales-Gay et al., 2009).

\section{Etiology}

\subsection{Implication of genetic factors}

Familial aggregation of GCA has been observed. Genetic predisposition has been reported with an association to the human leukocyte antigen (HLA)-DRB1 molecule, and tumor necrosis factor microsatellite polymorphisms. Moreover, many other studies have shown the implication of genetic variants in key components of immune and inflammatory pathways in GCA susceptibility, because GCA is a polygenic disease. An increased risk of having visual ischemic complications in biopsy-proven GCA patients was found to be associated with the carriage of HLA-DRB1*04 alleles. Moreover, a functional variant of the vascular endothelial growth factor gene was associated with severe ischemic complications in patients with GCA (Gonzales-Gay, 2001).

\subsection{Influence of infectious agents}

It has been proposed that infectious agents are a possible influence in the pathogenesis of GCA. Several infectious agents have been investigated as possible triggers in a susceptible host, with inconclusive results. Fluctuations of the incidence of GCA in different regions of Denmark, supporting an association with Mycoplasma pneumoniae, parvovirus B19, and Chlamydia pneumoniae epidemics, were found. An association of parvovirus B19 with GCA was also suggested by Gabriel et al., 1999. French investigators found an association of GCA with human parainfluenza virus type 1 (Gabriel et al., 1999).

Four different recent studies did not confirm any association between the presence of parvovirus B19, C pneumoniae, or human herpesvirus DNA in TAB specimens and the histologic evidence of biopsy-proven GCA (Rodriguez-Pla, 2004).

However, the presence of peaks in the incidence and a cyclic pattern observed in other studies suggests that infectious agents may play a role in the pathogenesis of both diseases. They could be the triggers for the development of these conditions in genetically predisposed individuals (Ghanchi, 1996).

\subsection{Influence of traditional cardiovascular risk factors}

(Duhaut et al, 1999), in a prospective multicenter case-control study on 207 biopsy-proven GCA patients, described a strong association between smoking and previous atheromatous disease in women and GCA. The presence of atherosclerosis risk factors at the time of diagnosis of the disease may influence the development of severe ischemic complications in patients with this vasculitis.

\section{Pathogenesis}

GCA is an autoimmune vasculitis. It involves predominantly medium-sized arteries, especially the superficial temporal, ophthalmic, posterior ciliary, and other peripheral arteries. The typically predominant extracranial vascular involvement is explained by the affinity of inflammation to the elastic fibers. As intracranial arteries have less elastic fibers in the media, they are seldomly involved. The severity and extent of the involvement are associated with the quantity of elastic tissue in the media of the artery. 
Two different types of inflammatory reactions are found in the temporal arteries in patients with GCA. One is related to foreign-body giant-cell reaction, directed at small calcifications of the internal elastic membrana. The foreign-body type of inflamation is focal, affecting only part of the arterial circumference. The other type of lesion is characterized by diffuse inflammation in which mononuclear inflammatory cells invade the layers of the arterial wall in the whole circumference of the vessel. (Weyand et al., 1997).

GCA is an antigen-driven disease with local $\mathrm{T}$ cell and macrophage activation in the vessel wall, and with an important role of proinflammatory cytokines. Inflammation of the arterial wall and vessel occlusion through fast and concentric intimal hyperplasia leads to the severe ischemic complications observed in patients with GCA. Dendritic cells localized at the adventitia-media border of normal medium-sized arteries produce chemokines and recruit and locally activate $\mathrm{T}$ cells. Moreover, dendritic cells express a singular surface receptor profile, including a series of Toll-like receptors (TLRs). Ligands of TLR-4 promote activation and differentiation of adventitial dendritic cells into chemokine-producing effector cells with high-level expression of both CD83 and CD86, and mediate T cell recruitment through the release of interleukin-18 (IL-18). Activated T cells experience clonal expansion and are stimulated to produce interferon-gamma (IFN-gamma). This leads to the differentiation and migration of macrophages and the formation of giant cells. In the adventitia, macrophages produce proinflammatory cytokines such as IL-1 and IL-6, whereas in the media and intima they contribute to arterial injury by producing metalloproteinases and nitric oxide.

This destructive mechanism of the arterial wall is associated with a repair mechanism that includes the secretion of growth and angiogenic factors (platelet-derived growth factor and vascular endothelial growth factor) through the infiltration of mononuclear cells and multinucleated giant cells. These changes ultimately lead to the degradation of the internal elastic lamina and to occlusive luminal hyperplasia. In addition to IL-1 and IL-6, IFNgamma specifically seems to play a pivotal role in the pathogenesis and in the clinical expression of GCA. In this regard, IFN-gamma is expressed in nearly $70 \%$ of the temporal artery biopsy (TAB) samples from patients with GCA. High transcription of IFN-gamma messenger RNA (mRNA) was associated with the formation of giant cells and with the evidence of cranial ischemic symptoms in GCA patients. The absence of IFN- gamma expression in TAB samples from patients with isolated PMR suggests that its production may be crucial to the development of GCA. TAB specimens from GCA patients with ocular ischemia expressed high amounts of IFN-gammamRNA, whereas those from GCA patients with fever had less IFN-gamma mRNA. Therefore, clinical correlates suggest a role of IFNgamma in the process of lumenal obstruction. By regulating giant cell formation, IFNgamma could indirectly control intimal hyperplasia. IFN-gamma may dictate the functional properties of other cell populations in the vascular infiltrates and, by means of this mechanism, guide the response-to-injury reaction of the artery (Weyand et al., 1997).

\section{Diagnosis}

A definitive diagnosis is made following the criteria of the American College of Rheumatology which include: age, temporal headache, swollen temporal arteries, jaw claudication, eye involvement, the temporal artery biopsy, and its histologic evaluation. The disease affects elderly patients, with a mean age of 70 years.

\section{Diagnostic criteria of temporal arteritis}

Three of the five diagnostic criteria for GCA have to be met (Hunder et al., 1990): 
1. Age 50 years or more.

2. New developed headache.

3. Tenderness of the superficial temporal artery.

4. Elevated sedimentation rate (ESR), at least $50 \mathrm{~mm} / \mathrm{h}$.

5. Giant cell arteritis in a biopsy specimen from the temporal artery.

Large vessel giant cell arteritis is a subgroup of GCA (temporal arteritis) described in at least $17 \%$ of cases. In these patients, inflammation occurs also at the level of the aorta and its branches (especially of the subclavian, the axillary arteries, etc), although symptoms of aortic involvement (aortic aneurysm rupture) may appear years after the initial diagnosis of this vasculitis (Martinez-Valle, 2010).

Interestingly, in some cases, the common carotid arteries (CCA) and the internal carotid arteries (ICA) are also involved.

\subsection{Clinical features}

The typical neurological symptoms and classic clinical features of GCA are presented by new moderate bitemporal headache, especially common at night, jaw claudication, scalp tenderness (which is first noticed when combing the hair), or abnormal superficial temporal arteries (tender, nodular, swollen, and thickened arteries) on palpation (Gonzales-Gay et al., 2005). (fig.1)

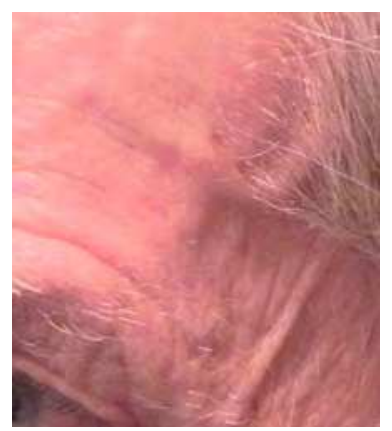

Fig. 1. Patient MM. Dilated and nodular left superficial temporal artery.

Initially, temporal pulsation is present, although the thickened arteries cann't be flattened against the skull. The best location to feel for pulsation is directly in front of the upper pole of the pinna of the ear. Later, the temporal arteries present a decreased pulsatility. Lack of pulsation is very suggestive of GCA because it is most unusual for the superficial temporal arteries to be non-pulsatile in normal elderly individuals. The jaw claudication is the result of ischemia of the masseter muscles, which causes pain on speaking and chewing.

A recent study aiming to establish the best set of clinical features that may predict a positive $\mathrm{TAB}$ in a community hospital disclosed that headache, jaw claudication, and abnormal temporal artery on palpation were the best positive predictors of positive TAB in patients on whom a biopsy was performed to diagnose GCA. These authors established clinical differences between biopsy proven GCA and biopsy-negative GCA patients. Moreover, they observed a non-significantly increased frequency of abnormal palpation of the temporal artery on physical examination in biopsy-proven GCA patients $(73.3 \%)$ compared with biopsy-negative GCA patients (54.2\%). 
Less common neurologic complications (approximately $4 \%$ of patients) include transient ischemic attacks, or stroke, more frequently in the posterior circulation, than in the carotid territory, manifested by homonymous hemianopsia or cortical blindness (unilateral or bilateral occipital infarction), and audiovestibular dysfunction. They occur more commonly at the time of GCA diagnosis or within the first 4 weeks after the onset of corticosteroid therapy. Almost all patients with GCA-associated strokes have a significant acute phase response with elevated ESR and C-reactive protein (CRP). The mortality has been reported to be as high as $75 \%$. The impact of cardiovascular risk factors on the occurrence of cerebral ischemic events has been evaluated in the Reggio Emilia region of Italy in patients with biopsy-proven TA. Both a history of hypertension or ischemic heart disease were associated with a higher risk of stroke (Berger et al., 2009).

Systemic symptoms includ fever, fatigue, malaise, weight loss, and/or polymyalgia rheumatica. Polymyalgia rheumatica (PMR) is a disease characterized by severe bilateral pain and aching involving the neck, shoulder, and pelvic girdles associated with morning stiffness. PMR is more common than GCA, and it may present as an isolated entity, or may be the presenting feature in patients who later develop typical cranial manifestations of GCA (Salvarani et al., 2008). Population-based studies have shown the presence of "silent" biopsy-proven GCA in 9-21\% of the patients presenting with PMR features. Also, PMR manifestations are observed in up to $40-50 \%$ of patients with biopsy-proven GCA. The nephritic syndrome has been reported in patients with GCA in the setting of focal segmental glomerulonephritis, membranous glomerulonephritis, amyloidosis, and necrotizing glomerulonephritis.

Ocular ischemic complications are the major source of chronic disability among GCA patients. In some cases, the development of blindness may be preceded by episodes of amaurosis fugax. They are generally early manifestations due to the vasculitic involvement of retrobulbar (orbital) vessels deriving from the ophthalmic artery (OA). In unselected patients with biopsy-proven GCA, visual ischemic complications occur in $25 \%$ and irreversible visual loss occurs in $10-15 \%$ of the patients. There is a significantly increased frequency of severe visual ischemic complications (transient or permanent visual loss) in the group of biopsy-proven GCA patients compared with GCA patients with a negative TAB. These interesting observations are in agreement with two previous population-based studies that disclosed that biopsy-negative patients have less frequency of severe ischemic complications than those with biopsy-proven GCA. Ocular ischemic complications are generally due to arteritic anterior ischemic optic neuropathy (AAION). More rarely, visual loss is caused by central retinal artery occlusion (CRAO), or ischemic retrobulbar neuritis (Gonzales-Gay et al., 2000).

Arteritic anterior ischemic optic neuropathy (AAION) results from short posterior ciliary arteries (SPCA) vasculitis and the consecutive optic nerve head infarction. Human autopsy studies of acute arteritic AION demonstrate optic disc edema with ischemic necrosis of the prelaminar, laminar, and retrolaminar portions of the optic nerve and infiltration of the SPCA by chronic inflammatory cells. In some cases segments of these vessels have been occluded by inflammatory thickening and thrombus (Arnold, 2004).

Patients with an unilateral AAION present the following key features:

a. abrupt, painless, severe loss of vision of the affected eye.

b. anterior segment examination of both eyes is normal.

c. the ophthalmoscopy of the affected eye reveales diffuse pale optic disc edema, but within 1-2 months, the swelling gradualy resolves and the entire optic disc will become atrophic. (fig.2) 


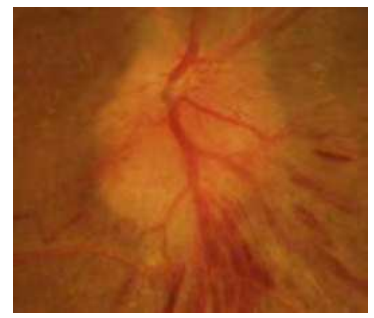

Fig. 2. Pacient TL-Fundus view of the left eye. Arteritic AION. The optic disc demonstrates pale, diffuse edema.

Typically, in AAION the severe visual loss is preceeded by transient visual loss similar to that of carotid artery disease. This symptom is unusual in the nonarteritic form of AION. The ophthalmoscopy indicates that pallor is associated with the edema of the optic disc more frequently in the arteritic than in the non arteritic form of AION. Although simultaneous bilateral involvement is rare in the arteritic form of $\mathrm{AION}$, about $65 \%$ of untreated patients become blind in both eyes within a few weeks. The optic disc of the fellow eye is of normal diameter, with a normal physiological cup (absence of "disk at risk", with postulated structural crowding of the axons at the level of the cribriform plate, associating mild disc elevation, and disc margin blurring without overt edema).

Central Retinal Artery Occlusion (CRAO) is the result of an abrupt diminuation of blood flow in CRA, severe enough to cause ischemia of the inner retina. Due to the fact that there are no functional anastomoses between choroidal (posterior ciliary arteries) and retinal circulation (CRA), CRAO determines severe and permanent loss of vision. Therefore, it is very important to identify the cause of CRAO, in order to protect the contralateral eye. Frequently, the site of the blockage is within the optic nerve substance and for this reason, it is generally not visible on the ophthalmoscopy (Ahuja et al., 1999).

Patients with an unilateral CRAO present the following key features:

a. abrupt, painless, severe loss of vision of the affected eye.

b. anterior segment examination is normal in both eyes.

c. the fundus of the affected eye presents: (fig 3)

- $\quad$ ischemic whitening of the retina.

- cherry-red spot in the center of the retina.

- the site of obstruction of CRA is not visible on ophthalmoscopy (no embolus is found).

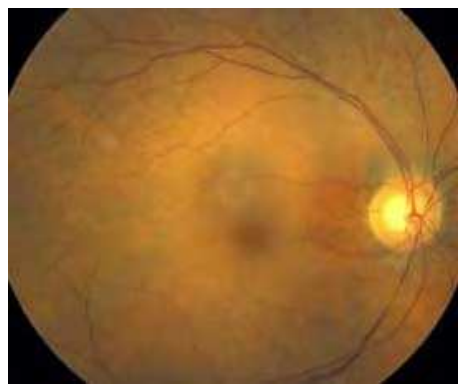

Fig. 3. Patient MM-Fundus view of the left eye. CRAO. A prominent cherry-red spot with cilio-retinal artery sparing in the papillomacular bundle. 
In only $20-25 \%$ of cases are emboli visible in the CRA or one of its branches, suggesting that an embolic cause is not frequent in CRAO (embolic material from either the heart, the ascending aorta or the ipsilateral ICA). It is currently believed that the majority of CRAO's are caused by thrombus formation due to systemic diseases: haematological disorders, and last but not least, systemic vasculitis (including GCA). For this reason, all patients with CRAO should undergo a systemic evaluation (Duker, 2004).

In CRAO the retina appears white as a result of cloudy swelling. The "cherry-red spot" appearence in the center of the retina is due to the relatively intact choroidal circulation, in contrast to the ischemic retina. (Duker, 2004).

\subsection{Laboratory findings}

Laboratory findings reveal a raised Erythrocyte sedimentation rate (ESR) and increased values of C-reactive protein (CRP). ESR is often very high in GCA, with levels more than 60 $\mathrm{mm} / \mathrm{hr}$. In interpreting the ESR it should be emphasized that the levels of $40 \mathrm{~mm} / \mathrm{hr}$ may be normal in the elderly and cases of biopsy- proven GCA have been reported in patients with ESR levels lower than $30 \mathrm{~mm} / \mathrm{hr}$. Approximately $20 \%$ of patients with GCA have a normal ESR. CRP is invariably raised in GCA and may be helpful when the ESR is equivocal (Lopez-Diaz, 2008). This acute phase response is induced by pro-inflammatory cytokines, mainly interleukins (IL) 1,6 and tumor necrosis factor (TNF) alpha. These are produced by activated macrophages in the vessel wall. The target antigen of the CD4+ T cell immune response in GCA is probably located in the internal elastic layer of the vessel wall which explains that arteries of the anterior intracerebral circulation are infrequently affected because these lack an internal elastic layer (Weyand et al., 2003).

Several imaging modalities may be useful to make a diagnosis of GCA. In this regard, Pipitone et al., 2008performed an elegant review of the role of imaging studies in the diagnosis and follow-up of large vessel vasculitis (Pipitone et. al., 2008).

\subsection{Extracranial Duplex sonography}

Ultrasonography (US) of the temporal artery has raised great interest in the diagnosis of GCA. Extracranial Duplex sonography investigates almost completely the whole length of the common superficial temporal arteries, including the frontal and parietal branches, and founds that inflammation is segmental (discontinous arterial involvement). The common superficial temporal artery derives from the external carotid artery. It divides into the frontal and parietal ramus in front of the ear. The distal common superficial temporal artery and the rami are localized between the two layers of the temporal fascia, which is like a bright band at ultrasound examination (Schmidt, 2006).

\section{Technical requirements}

High-resolution color Doppler US can show the vessel wall and the lumen of the temporal arteries. One should use linear probes with a minimum gray scale frequency of $8 \mathrm{Mhz}$. Color frequency should be about $10 \mathrm{Mhz}$ (Schmidt, 2006).

\section{Machine adjustments}

The pulse repetition frequency (PRF) should be about $2.5 \mathrm{khz}$ as maximum systolic velocities are rather high $(20-100 \mathrm{~cm} / \mathrm{s})$. Steering of the color box and the Doppler beam should be maximal as the rami are paralel to the probe. It is important that the color covers the artery lumen exactly (Schmidt, 2006). 


\section{Sonographer training}

The sonographer should perform at least 50 Duplex ultrasound of the temporal arteries of subjects without GCA to be sure about the appearance of normal temporal arteries before starting to evaluate patients with GCA (Schmidt, 2006).

\section{Sequence of the Ultrasound examination}

The investigation should start at the common superficial temporal artery using a longitudinal scan. The probe should then be moved along the course of the temporal artery to the parietal ramus. On the way back one should deliniate the temporal artery in transverse scans. Using the transverse scan, one can find the frontal ramus, which should then be delineated in both scans (longitudinal and transverse). If the color signals indicates localized aliasing and diastolic flow, one should use the pw-Doppler mode to confirm the presence of stenoses (Schmidt, 2006).

Schmidt et al., 1997 demonstrated that the most specific (almost 100\% specificity) and sensitive (73\% sensitivity) sign for GCA was a concentric hypoechogenic mural thickening, dubbed halo, which the authors interpreted as vessel wall edema. Other positive findings for GCA are the presence of occlusion and stenosis (Schmidt et al., 1997).

In conclusion, three findings are important for the ultrasound diagnosis of temporal arteritis:

a. "dark halo" sign - a typically hypoechoic, circumferential wall thickening around the lumen of an inflamed temporal artery - which represents vessel wall edema and a characteristic finding in temporal arteritis (TA)/GCA (Arida et al., 2010).

b. stenoses are documented by blood-flow velocities, which are more than twice the rate recorded in the area of stenosis compared with the area before the stenosis, with wave forms demonstrating turbulence and reduced velocities behind the area of stenosis. (fig.4.A,B).

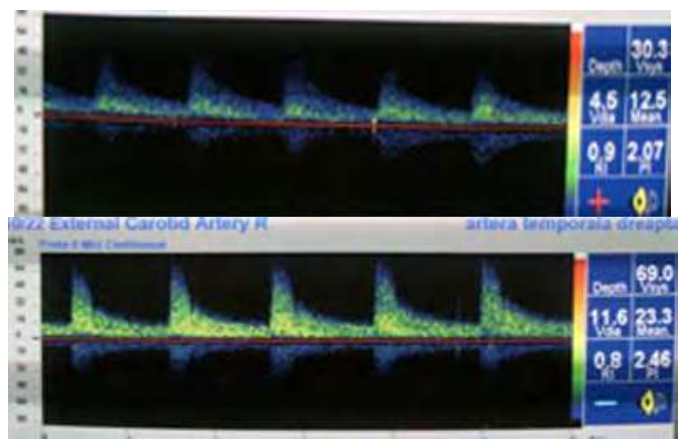

Fig. 4. Patient TL-Spectral analysis CW- 8Mhz -Extracranial Doppler ultrasound of the right temporal artery.

a. Peak flow velocity is $69 \mathrm{~cm} / \mathrm{s}$ in the area of stenosis, and

b. $\quad 30.3 \mathrm{~cm} / \mathrm{s}$ before the stenosis.

c. acute occlusions, in which the ultrasound image is similar to that of acute embolism in other vessels, showing hypoechoic material in the former artery lumen with absence of color signals (Schmidt et al., 1997).

Similar ultrasound patterns can be found in other arteries: the facial, the internal maxilary, the lingual, the distal subclavian, and axilary arteries. (fig.5A,B.) 


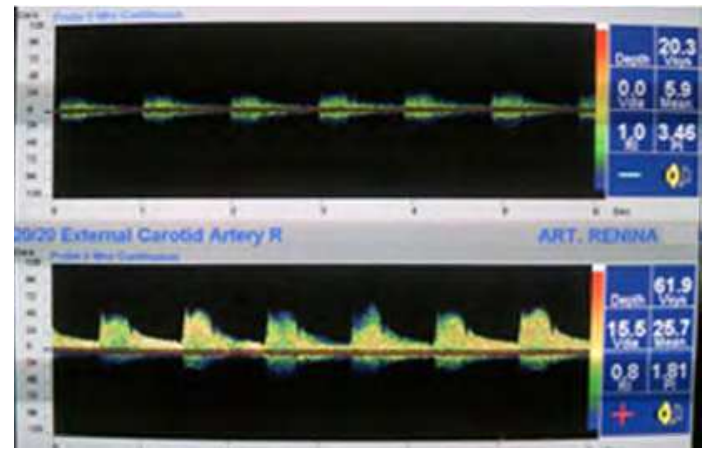

Fig. 5. Patient TL-Spectral analysis CW- 8Mhz -Extracranial Doppler ultrasound of the left lingual artery.

a. Peak flow velocity is $61.9 \mathrm{~cm} / \mathrm{s}$ in the area of stenosis, and

b. $20.3 \mathrm{~cm} / \mathrm{s}$ before the stenosis.

Interestingly in some cases the common carotid and the internal carotid arteries (the CCA and the ICA) are also involved (large-vessel giant cell arteritis).(fig.6, fig.7).

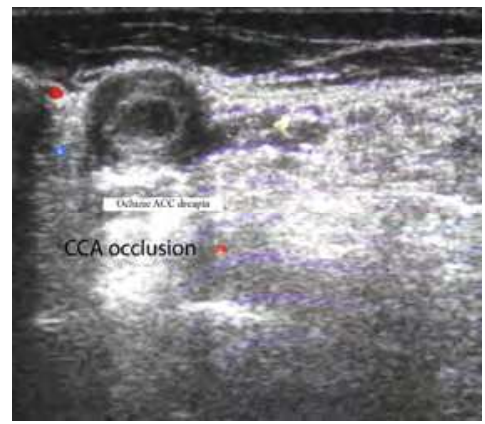

Fig. 6. Patient MM-B mode insonation in large vessel giant cell arteritis. Transverse view of the left CCA. Hypoechoic wall swelling with CCA occlusion.

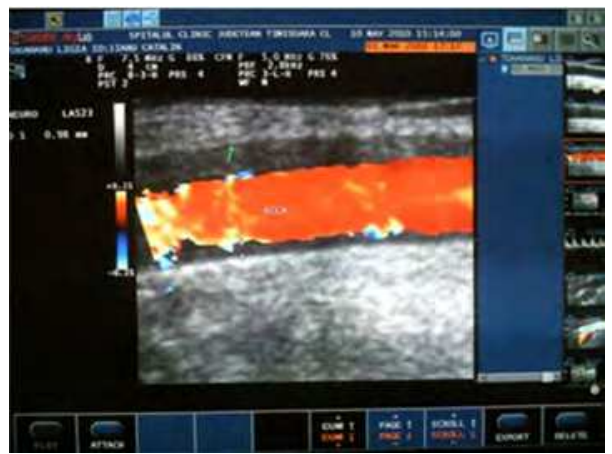

Fig. 7. Patient TL-Color Doppler ultrasound in large vessel giant cell arteritis. Longitudinal view of the right CCA with hypoechoic wall swelling. 
Ultrasound investigation has to be performed before corticosteroid treatement, or within the first 7 days of treatment, because with corticosteroid therapy the "halo" revealed by temporal arteries ultrasound disappeares within 2-3 weeks. The wall swelling, stenoses, or occlusions of the larger arteries (CCA, ICA) remaines for months, despite the corticosteroid therapy. Nevertheless, diagnostic assessment should not delay the start of therapy. Ultrasound may also detect inflamed temporal arteries in patients with clinically normal temporal arteries. Some patients with the clinical image of polymyalgia rheumatica, but with occult temporal arteritis may be diagnosed by ultrasonography.

Arida et al., 2010 looked for studies that examined the sensitivity and specificity of the "halo" sign demonstrated by temporal artery US for GCA diagnosis versus the American College of Rheumatology (ACR) 1990 criteria for the classification of this vasculitis (used as a reference standard). Only 8 studies involving 575 patients, 204 of whom received the final diagnosis of GCA, fulfilled the technical quality criteria for US. This metaanalysis disclosed a sensitivity of $68 \%$ and a specificity of $91 \%$ for the unilateral ",halo" sign, as well as $43 \%$ and $100 \%$, respectively, for the bilateral "halo" sign in temporal artery US for GCA diagnosis when the 1990 ACR criteria are used as the reference standard. The authors confirmed that the halo sign in US is useful in diagnosing GCA (Arida et al., 2010).

Schmidt, 2006 compared the results of temporal artery US examinations with the occurrence of visual ischemic complications in patients with GCA. These US results were compared with the occurrence of AAION, CRAO, branch retinal artery occlusion, diplopia, or amaurosis fugax in 222 consecutive patients with newly diagnosed, active GCA. However, findings of temporal artery US did not correlate with eye complications (Schmidt, 2006).

\subsection{Color Doppler Imaging (CDI) of retrobulbar vessels}

We used a sonographer with 8-15 MHz linear probe for detecting (by Color Doppler sonography), and measuring (by spectral analysis pulsed Doppler sonography) the blood flow in the orbital vessels: the ophthalmic artery-OA; the central retinal artery-CRA and vein-CRV, posterior ciliary arteries-PCA, and the superior ophthalmic vein-SOV (Tranquart et al., 1997).

The patients with an unilateral arteritic AAION present at the Spectral Doppler analysis of the retrobulbar vessels the following aspects:

a. an increased resistance index (RI) in the posterior ciliary arteries (PCA) (the RI is higher on the affected side, than it is on the unaffected side); with severe diminished blood flow velocities (especially end-diastolic velocities) in the PCA. (fig.8.A, B,C,D)

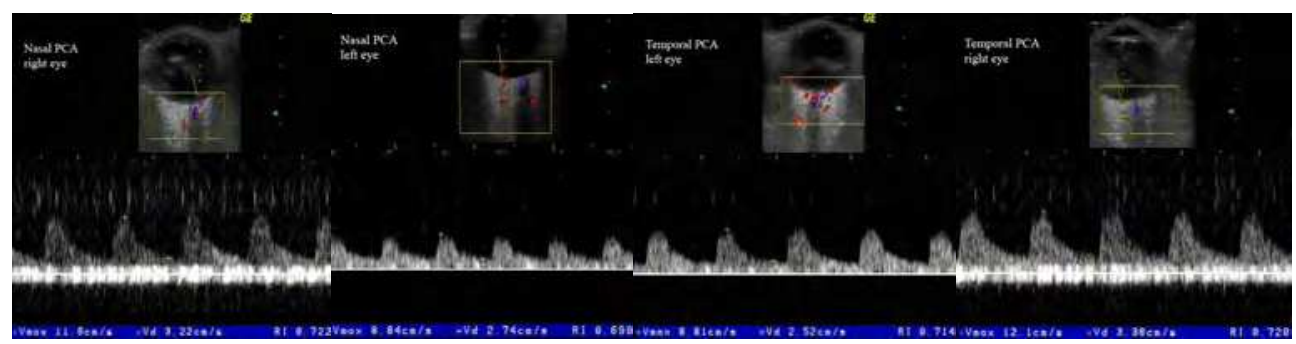

Fig. 8. A,B,C,D. Pacient TL-Spectral Doppler analysis of PCA. 
b. less abnormalities are observed in the central retinal arteries (CRA) (fig.9.A,B) and in the ophthalmic arteries (OA). (fig.10.A,B)

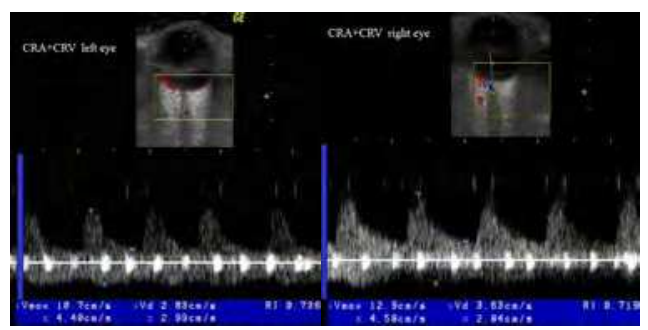

Fig. 9. A,B.Pacient TL-Spectral Doppler analysis of CRA.

In conclusion, the Spectral Doppler Analysis of the orbital vessels in arteritic AION reveales low blood velocities, especially end-diastolic velocities, and high RI in all retrobulbar vessels, in both orbits (with severe diminished blood flow velocities in the PCA, especially on the affected side). In nonarteritic AION blood velocities and RI in PCA are relatively preserved (Jianu D.\&Jianu S., 2010).

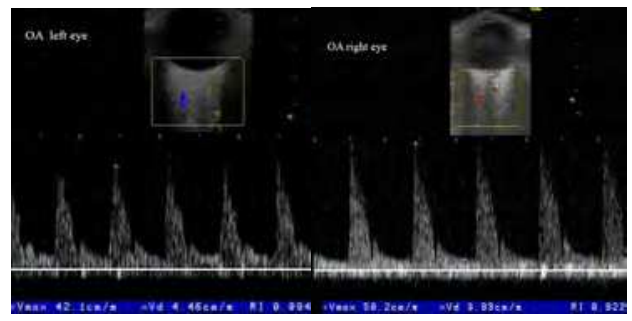

Fig. 10. A,B.Pacient TL-Spectral Doppler analysis of OA.

Fluorescein angiogram and CDI of retrobulbar vessels data support the histopatological evidence of involvement of the entire trunck of the SPCA in the arteritic AION (impaired optic disc and choroidal perfusion in the patients with arteritic AION). In contrast, in the nonarteritic AION, the impaired flow to the optic nerve head is distal to the SPCA themselves, possibly at the level of the paraoptic branches (only $1 / 3$ of the flow of the SPCA) (Collignon-Robe et al., 2004). These branches supply the optic nerve head directly (impaired optic disc perfusion, with relatively conservation of the choroidal perfusion). (fig.11)

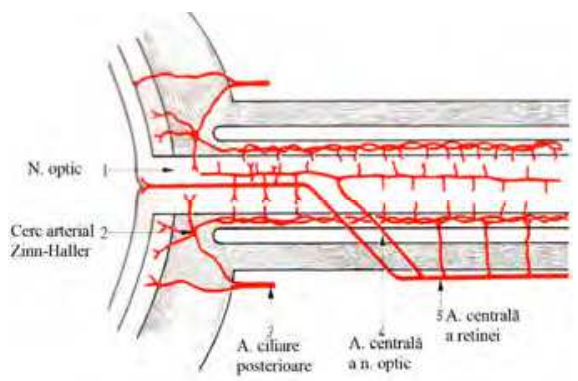

Fig. 11. Arterial vascularisation of the optic nerve. 
Extremely delayed or absent filling of the choroid has been depicted as a fluorescein angiogram characteristic of arteritic AION and has been suggested as one useful factor by which arteritic AION can be differentiated from nonarteritic AION.

The patients with an unilateral CRAO present at the Spectral Doppler analysis of the retrobulbar vessels the following aspects (Connolly, 2000):

a. an increased resistance index (RI) in the central retinal arteries- CRA (the RI is higher on the affected side, than it is on the unaffected side); with severe diminished blood flow velocities (especially end-diastolic velocities) in the CRA. (fig.12. A, B)

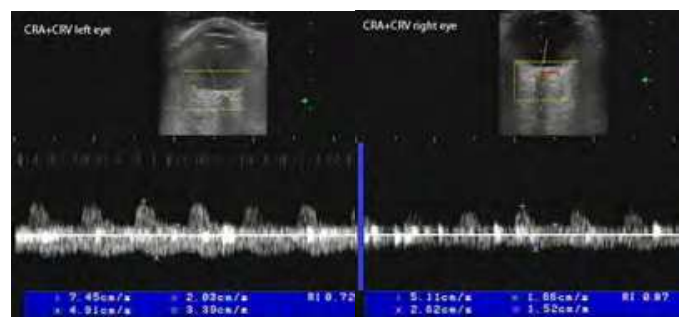

Fig. 12. A,B.Pacient MM-Spectral Doppler analysis of CRA.

b. less abnormalities are observed in the posterior ciliary arteries (PCA), (fig.13.A,B) and in the ophthalmic arteries (OA). (fig.14.A,B)

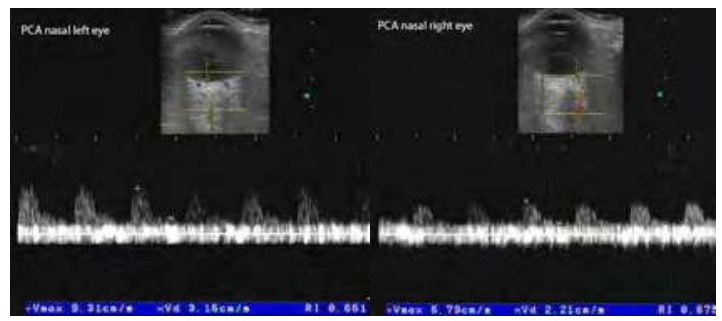

Fig. 13. A,B.Pacient MM-Spectral Doppler analysis of PCA.

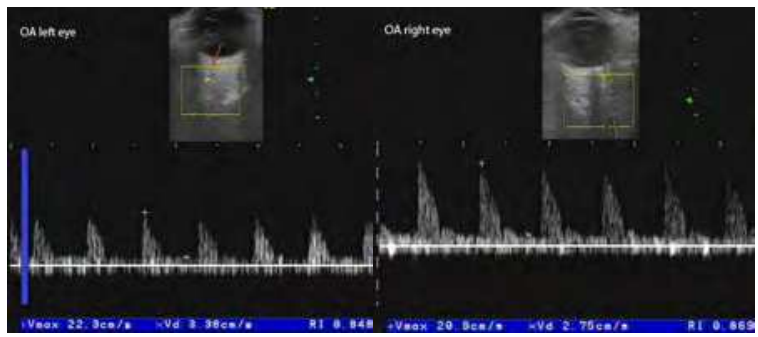

Fig. 14. A,B.Pacient MM-Spectral Doppler analysis of OA.

\subsection{Others imaging techniques}

Inflammation of the aorta and its branches may occur in a subset of GCA patients, although symptoms of aortic involvement may appear years after the initial diagnosis of this vasculitis (large giant cell arteritis). Therefore, as emphasized by Martinez-Valle et al., 2010 a 
systematic evaluation of patients with imaging techniques such as magnetic resonance angiography (MRA), computed tomographic angiography (CTA), or positron emission tomography (PET) may reveal that the clinical impact of extracranial involvement by GCA is more relevant than previously thought (Martinez-Valle et al., 2010).

Contrast-enhanced, high-resolution MR imaging allows noninvasive assessment of the mural inflammation. In this regard, Bley et al., 2008 compared the results of high-resolution MRI and color coded duplex US in 59 patients with suspected GCA with the final clinical diagnosis based on the ACR classification criteria for GCA (Bley et al., 2008). Thirty-six of the 59 patients $(61 \%)$ were ultimately diagnosed as having GCA. Sensitivity of high resolution MRI and color-coded duplex US was $69 \%$ and $67 \%$, respectively, while specificity was $91 \%$ in both. Temporal artery biopsy findings were positive in 24 of the 41 biopsied patients (59\%). Sensitivity of high-resolution MRI and color-coded duplex US compared with temporal artery biopsy was $83 \%$ and $79 \%$, respectively, and specificity was $71 \%$ and $59 \%$, respectively. Therefore, differences between high-resolution MRI and color-coded duplex US were not significant. According to these observations, the diagnostic power of high-resolution MRI and color-coded duplex US in detecting GCA was comparable. These authors suggest that both noninvasive techniques may be useful in the assessment of patients with suspected GCA.

However, these results are in contrast to those of another study performed in patients with suspected GCA. Ghinoi et al., 2008 performed an interesting study to determine the usefulness of $1 \mathrm{~T}$ MRI of the temporal arteries and to compare $1 \mathrm{~T}$ MRI with duplex US and physical examination of temporal arteries in the diagnosis of GCA in a series of 20 patients with suspected GCA (Ghinoi et al., 2008). Mural contrast enhancement of the temporal arteries on MRI had a sensitivity of $33.3 \%$ and a specificity of $87.5 \%$ for the diagnosis of biopsy-proven GCA. Compared with the diagnosis of GCA by the ACR classification criteria, 1 T MRI of the temporal arteries had a sensitivity and specificity of $27.2 \%$ and $88.9 \%$, respectively. Temporal artery abnormalities on physical examination and the presence of a hypoechoic halo on US had a higher sensitivity (66.7\% and $77.7 \%$, respectively) and a higher specificity. According to these observations, 1 T MRI does not seem useful in the diagnosis of GCA due to its low sensitivity.

Computed tomodensitometric scan allows analysis of the arterial wall and endoluminal part of the aorta and its branches. (fig.15)

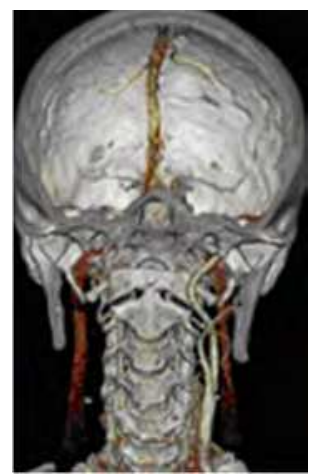

Fig. 15. Patient MM with large giant cell arteritis-CT-Angiography. Occlusion of the left CCA, $E C A$, and ICA. 
Because aortitis is a complication of GCA, Agard et al., 2008 conducted a study in a series of 22 patients and 22 controls using computed tomodensitometric scan to assess the presence of aortic abnormalities in patients with recent onset GCA. Thickening of the aortic wall was more frequent among patients with GCA than controls (Agard et al., 2008).

18 Fluorodeoxyglucose (FDG)-PET may be useful to detect large vessel arteritis in the setting of GCA, which can involve the larger thoracic, abdominal, and peripheral arteries. It may be particularly useful in the diagnosis of GCA patients with atypical presentations such as fever of unknown origin or those presenting with asthenia, anorexia, and weight loss without cranial ischemic manifestations. Also, as emphasized by Pipitone et al., 2008 previous reports showed that PET may be more sensitive than MRI in detecting vessel inflammation in the early stage of large giant cell arteritis (Pipitone et al., 2008). However, PET cannot detect inflammation in the temporal arteries; therefore, it is not adequate for the diagnosis of cranial GCA and cannot replace temporal artery biopsy. Moreover, relapses of GCA cannot be predicted by results of previous PET (Henes et al., 2008).

In conclusion, PET/CT seems useful in the diagnosis and re-evaluation of large vessel vasculitis. It allows the evaluation of disease activity and vessel morphology as well as the localization of the inflammatory process in the same session.

\subsection{Temporal Artery Biopsy (TAB) and the histopathologic picture}

A temporal artery biopsy (TAB) is the gold standard test for the diagnosis of GCA (Duhaut, Pinede, 1999). European League Against Rheumatism recommendations emphasize that TAB should be performed whenever a diagnosis of GCA is suspected. Because corticosteroid therapy is required in most cases for more than 1 year in GCA, the pathologic confirmation of this vasculitis is advisable. However, GCA affects vessels focally and segmentally, yielding areas of inflammatory vasculitic lesions juxtaposed with areas of normal artery. Histologic signs of inflammation may be missed in TABs performed in arteritis-free segments (Foroozan, 2003). Because of segmental (discontinous) involvement of temporal arteries, a biopsy result may be negative in $9-44 \%$ of patients with clinical positive signs of temporal arteritis; for this reason the temporal arteries biopsy has to be guided by Doppler Ultrasonography and typical clinical features (tender, swollen portions of temporal arteries). Prior treatment with steroids for more than 7 days may be associated with loss of the histological features of active arteritis. As a consequence, the ultrasound investigations and temporal arteries biopsy has to be performed before corticosteroid treatment. Interestingly, 2 population-based studies have shown that patients with negative biopsy samples have less frequency of severe ischemic complications than those with biopsyproven GCA (Breuer, 2009).

Taylor-Gjevre et al., 2005 noted that a threshold length of $1.0 \mathrm{~cm}$ of postformalin fixed arterial segment was associated with an increased diagnostic yield of GCA (Taylor-Gjevre et al., 2005). They recommended collecting a minimum TAB length of $1.5 \mathrm{~cm}$ to allow for tissue shrinkage during fixation that was estimated to be about $10 \%$. More recently, Mahr et al., 2006 reported that a postformalin fixed TAB length of at least $0.5 \mathrm{~cm}$ could be sufficient to make a histologic diagnosis of GCA (Mahr et al., 2006). TAB is generally performed on the most symptomatic side. Breuer et al., 2009 performed a study to establish the relationship between TAB length and the diagnostic sensitivity for GCA (Breuer et al., 2009). In this study, the TAB in the subgroup of biopsy-positive GCA patients was significantly longer than in biopsy-negative GCA cases. The rate of positive biopsies was only $19 \%$ with TAB length of $5 \mathrm{~mm}$ or less but increased to $71-79 \%$ with TAB lengths of $6-20 \mathrm{~mm}$, and to $89 \%$ 
when TAB length was longer than $20 \mathrm{~mm}$. Only 3\% of positive biopsies were $5 \mathrm{~mm}$ or shorter. These authors concluded that TABs with postfixation length shorter than $5 \mathrm{~mm}$ yield an increased biopsy negative rate. As a result, the authors supported the claim that a TAB length longer than $5 \mathrm{~mm}$ is required for accurate diagnosis of GCA.

In the presence of unilateral ocular involvement, we took a biopsy from the ipsilateral side representing $2.5 \mathrm{~cm}$ of the tender, swollen segments of the affected artery („skip lesions"). Serial sections were examined, as there could be variations in the extent of involvement along the length of the artery (Gonzales-Gay et al., 2001).

However, due to the segmental inflammatory involvement of the temporal artery, a contralateral biopsy may be required in patients with high clinical suspicion of GCA. Breuer et al., 2009 found that performing bilateral TABs increases the diagnostic sensitivity of the procedure by up to $12.7 \%$ compared with unilateral biopsies (Breuer et al., 2009).

The definitive diagnosis of GCA requires the pathologic demonstration of a vasculitis with mononucleated cell infiltrates of all mural layers and occurrence of giant cells on a temporal artery biopsy. The degree of intimal hyperplasia on histology findings is associated with neuroophthalmic complications (Makkuni et al., 2008); the presence of giant cells in particular is associated with permanent visual loss (Chatelain et al., 2009).

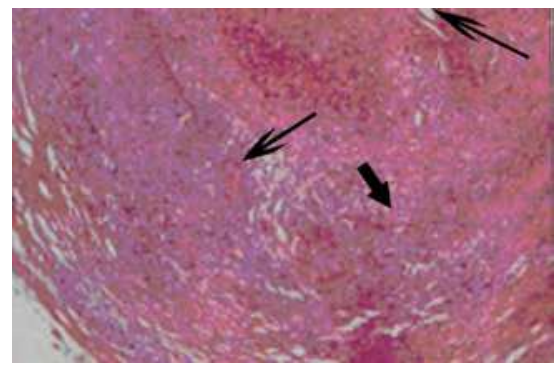

Fig. 16. Typical temporal arteritis Patient TL. Higher magnification showing the typical giant cell granulomatous inflammation.

Patient TL. Higher magnification showing the typical giant cell granulomatous inflammation.

In our cases we observed a granulomatous inflammation of the media layer (chronic inflammatory infiltrate with giant cells), with characteristic fragmentation of the internal limiting lamina and intimal thickening. (fig. 16)

\section{Treatment and evolution}

High-dose corticosteroids are the only effective therapy in GCA. Corticosteroid treatment must not be delayed by temporal artery biopsy, because the biopsy is positive even after a few days of steroid treatment. The initial dose of prednisone or its equivalent ranges between 40 and $60 \mathrm{mg} / \mathrm{d}$, as a single or divided dose, for 3-4 weeks .

In our experience, GCA patients without severe ischemic complications have rapid disease improvement with an initial prednisone dose of $40 \mathrm{mg} / \mathrm{d}$. In these patients, the use of corticosteroids has dramatically reduced the frequency of severe visual ischemic complications. 
However, in GCA patients who present with visual ischemic manifestations we use higher corticosteroid doses - generally an initial intravenous methyl prednisolone pulse therapy (1 $\mathrm{g} / \mathrm{d}$ for 3 consecutive days), followed by oral prednisone $60 \mathrm{mg}$ daily for 3-4 weeks.

To assess whether corticosteroid therapy should be given every other day or as a single or divided daily dose, Hunder et al., 1975 carried out a prospective, randomized study to compare oral prednisone treatment in a divided dose t.i.d. $(15 \mathrm{mg} / 8 \mathrm{~h})$ with a single daily dose of prednisone $(45 \mathrm{mg}$ ) and prednisone every other morning $(90 \mathrm{mg}$ ) (Hunder et al., 1975). After 1 month of treatment, they found a trend toward better disease control in the divided dose group compared with the single daily dose group, but no differences in the side effect profile between the two groups. However, in only 6 of the 20 patients receiving prednisone every other morning was the disease completely suppressed. These results support the need to start treatment with daily prednisone therapy in patients with GCA.

A study compared an initial high-dose pulse of IV methylprednisolone versus classic corticosteroid therapy. The authors performed a double-blind, placebo controlled, randomized, prospective clinical trial: a 3-day course of IV methyl prednisolone pulses (15 $\mathrm{mg} / \mathrm{kg}$ of ideal body weight/d) in addition to the oral prednisone $(\mathrm{n}=14)$ compared with normal IV saline infusions plus oral prednisone $(n=13)$. The initial IV pulse of methylprednisolone therapy yielded more rapid corticosteroid tapering, lower median dose at each visit, and fewer relapses. However, further studies including larger numbers of patients are required to establish the routine use of IV pulse methylprednisolone as the initial corticosteroid therapy for the management of GCA (Mazlumzadeh et al., 2006).

Data show that it is not the absolute dose but rather the time from the onset of symptoms to the first administration of corticosteroids that is predictive of improvement of visual loss. Regrettably, in most cases, once established, the prognosis for significant visual recovery in GCA patients despite corticosteroid therapy is poor. Gonzalez-Gay et al. 2000 assessed the outcome of 29 GCA patients who developed loss of vision shortly before their admission to the hospital (Gonzalez-Gay et al. 2000). Only 8 patients (28\%) experienced visual improvement-generally partial-following corticosteroid therapy. The main factor influencing the response to corticosteroids was therapeutic delay. Interestingly, 7 of 12 patients treated within the first $24 \mathrm{~h}$ after the onset of visual loss experienced visual improvement. However, when corticosteroid therapy was delayed for more than 1 day, only 1 of the remaining 17 patients experienced some visual recovery. These observations indicate that corticosteroid therapy should not be delayed under any circumstances in GCA patients with suspected visual impairment.

In conclusion the aim of the treatment in patients with GCA with eye involvement is to prevent blindness of the fellow eye, although in a few unfortunate patients with initial unilateral visual loss, the second eye also became blind inspite of prompt steroid administration (Gonzales-Gay et al., 1998). Most GCA symptoms other than blindness (headache, etc) usually begin to improve within 24-72 h after the onset of corticosteroid therapy. Also, normalization of routine laboratory parameters of inflammation (ESR and CRP) occurs within 2-4 weeks after initiation of this therapy. Afterward, the corticosteroid dose can be tapered gradually. However, the duration of corticosteroid therapy is variable, and relapses often occur. Whenever symptoms or acute phase proteins recur during tapering, the last effective dose plus $10 \mathrm{mg}$ should be administered Prednisone is generally reduced by $5 \mathrm{mg}$ every 2-4 weeks down to $25 \mathrm{mg}$. Then it can be reduced by $2.5 \mathrm{mg}$ every $2-$ 4 weeks until the dose is $10 \mathrm{mg}$, and later by about $2.5 \mathrm{mg}$ every 2 months. Prednisone tapering is then performed more slowly (Gonzales-Gay et al., 2005). 
The duration of treatment (1-2 years ) is guided by the patient's symptoms and the levels of the ESR and CRP. In some cases from the literature, symptoms may however recur without a corresponding increase in ESR or CRP or vice versa, requiring indefinite maintenance therapy (Gonzales-Gay et al., 2005).

Up to $80 \%$ of patients with GCA experience complications related to steroid therapy. These include diabetes mellitus, osteoporosis with vertebral compression fractures and Cushing syndrome. It is advisable to consider the use of bone protection therapy in patients with GCA (Gonzales-Gay et al., 2005).

In this regard, alternative corticosteroid-sparing drugs - in particular methotrexate (MTX)should be considered in GCA patients with severe corticosteroid-related side effects and/or in patients who require prolonged corticosteroid therapy due to relapses of the disease. With respect to this, to reevaluate the efficacy and safety of adjunctive low-dose MTX in GCA patients, Mahr et al., 2006 performed an individual patient data meta-analysis of three randomized, placebo-controlled trials in patients with newly diagnosed GCA (Mahr et al., 2006). However, the authors found a modest role of MTX (10-15 mg/ wk) in reducing relapse rate and decreasing the cumulative corticosteroid therapy.

In small trials, anti-tumor necrosis factor-a therapy (infliximab and etanercept) have been evaluated in patients with GCA and toxicity secondary to steroid therapy. No clear benefit of anti-tumor necrosis factor- $\alpha$ therapy in patients with GCA has been reported. Moreover, the limited number of patients on tumor necrosis factor- $\alpha$ blocker agents included in these studies does not allow us to draw definitive conclusions about these drugs (Gonzales-Gay et al., 2005).

It is known that the presence of traditional atherosclerosis risk factors at the time of diagnosis of GCA influences the development of severe ischemic manifestations in patients with this type of vasculitis. Interestingly, two retrospective studies suggested that antiplatelet and/or anticoagulant therapy may reduce ischemic complications in patients with GCA (Nesser et al., 2004). Therefore, antiplatelet therapy started before GCA diagnosis may reduce the risk of severe ischemic events in patients with GCA. Thus, aspirin $(75-125 \mathrm{mg} / \mathrm{d})$ should be prescribed in patients with GCA. However, no positive impact of antiaggregation therapy on the risk of severe ischemic complications has been confirmed in more recent studies (Lee et al., 2006).

\section{Conclusions}

GCA is a common disease among older adults from Western countries. Higher physician awareness may have been responsible for the progressive increase in the incidence of these conditions observed in different parts of the world. Diagnostic criteria of GCA are represented by age 50 years or more, new develop headache, tenderness of the superficial temporal artery, elevated ESR, at least $50 \mathrm{~mm} / \mathrm{h}$, and giant cell arteritis in a biopsy specimen from the temporal artery. Large vessel giant cell arteritis is a subgroup of GCA occuring also at the level of the aorta and its branches (especially of the subclavian, the axillary arteries, etc.).

The eye involvement in Horton's disease consists in anterior ischemic optic neuropaty or central retinal artery occlusion with abrupt, painless, and severe loss of vision of the involved eye.

The superficial temporal artery biopsy is the gold standard test for the diagnosis of this vasculitis. Several imaging modalities, particularly US, are useful in making a diagnosis of 
GCA (,dark halo" sign). However, findings of temporal artery US did not correlate with eye complications. For this reason, Color Doppler Imaging of the retrobulbar vessels may be helpful to detect the blood flow in the orbital vessels, especially in cases of opacity of the medium, or when the clinical appearance of ophthalmologic complications in temporal arteritis is athypical. The Spectral Doppler Analysis of the orbital vessels in GCA reveales low blood velocities, especially end-diastolic velocities, and high resistance index in all retrobulbar vessels, in both orbits, for all patients (especially on the affected side).

Corticosteroids are the cornerstone of treatment in GCA. Alternative corticosteroid- sparing drugs, in particular MTX, should be considered in GCA patients with severe corticosteroidrelated side effects and/or in patients who require prolonged corticosteroid therapy due to relapses of the disease.

Key words: Giant cell arteritis, temporal headache, superficial temporal artery biopsy, "dark halo" sign, central retinal artery obstruction, arteritic anterior ischaemic optic neuropathy.

\section{References}

Agard C, Barrier JH, Dupas B, et al. (2008): Aortic involvement in recent-onset giant cell (temporal) arteritis: a case-control prospective study using helical aortic computed tomodensitometric scan. Arthritis Rheum 2008, 59:670-676.

Ahuja R.M., Chaturvedi S., Elliot A., et al. (1999) - Mechanism of retinal arterial occlusive disease in African, American and Caucasian patients, Stroke 1999 Aug; 30(8): 479-84.

Arida A, Kyprianou M, Kanakis M, Sfikakis PP (2010): The diagnostic value of ultrasonography-derived edema of the temporal artery wall in giant cell arteritis: a second meta-analysis. BMC Musculoskelet Disord 2010, 11:44.

Arnold A.C. (2004) - Chapter 191 - Ischemic optic neuropathy, in Ianoff M., Duker J.S., ed., Ophtalmology, second edition, Mosby, 2004:1268-1272.

Berger CT, Wolbers M, Meyer P, et al.(2009): High incidence of severe ischaemic complications in patients with giant cell arteritis irrespective of platelet count and size, and platelet inhibition. Rheumatology (Oxford) 2009, 48:258-261.

Bley TA, Reinhard M, Hauenstein C, et al.(2008): Comparison of duplex sonography and high-resolution magnetic resonance imaging in the diagnosis of giant cell (temporal) arteritis. Arthritis Rheum 2008, 58:2574-2578.

Breuer GS, Nesher R, Nesher G (2009): Effect of biopsy length on the rate of positive temporal artery biopsies. Clin Exp Rheumatol 2009, 27(Suppl 52):S10-S13.

Collignon-Robe N.J., Feke G.T., Rizzo J.F. (2004) - Optic nerve head circulation in nonarteritic anterior ischemic optic neuropathy and optic neuritis, Ophthalmol. 2004; 111: 1663-72.

Connolly B.P., Krishnan A., Shah G.K., Whelan J., Brown G.C., Eagle R.C. Jr., Shakin E.P. (2000) - Characteristics of patients presenting with central retinal artery occlusion with and without giant cell arteritis, Can. J. Ophthalmol. 2000 Dec; 35(7):379-84.

Duhaut P, Bosshard S, Calvet A, Pinede L, Demolombe-Rague S, Dumontet C, et al (1999), for the Groupe de Recherche sur l'Arterite a' Cellules Geantes. Giant cell arteritis, polymyalgia rheumatica, and viral hypotheses: a multicenter, prospective casecontrol study. J Rheumatol 1999;26:361-9.

Duhaut $\mathrm{P}$, Pinède L, Bornet $\mathrm{H}$, et al.(1999): Biopsy proven and biopsy negative temporal arteritis: differences in clinical spectrum at the onset of the disease. Groupe de Recherche sur l'Artérite à Cellules Géantes. Ann Rheum Dis 1999, 58:335-341. 
Duker J.S.(2004), - Chapter 114 - Retinal arterial obstruction, in Yanoff M., Duker J.S., ed., Ophtalmology, second edition, Mosby, 2004:856-63.

Foroozan R, Deramo VA, Buono LM, et al.(2003): Recovery of visual function in patients with biopsy-proven giant cell arteritis. Ophthalmology 2003, 110:539-542.

Gabriel SE, Espy M, Erdman DD, Bjornsson J, Smith TF, Hunder GG (1999). The role of parvovirus B19 in the pathogenesis of giant cell arteritis: a preliminary evaluation. Arthritis Rheum 1999;42:1255-8.

Ghanchi F.D., Williamson T.H., Lim C.S., Butt Z., Baxter G.M., McKillop G., O`Brien C.(1996) - Color Doppler imaging in giant cell (temporal) arteritis: serial examination and comparison with non-arteritic anterior ischaemic optic neuropathy, Eye 1996; 10(4):459-64.

Ghinoi A, Zuccoli G, Nicolini A, et al.(2008): $1 \mathrm{~T}$ magnetic resonance imaging in the diagnosis of giant cell arteritis: comparison with ultrasonography and physical examination of temporal arteries. Clin Exp Rheumatol 2008, 26(Suppl 49):S76-S80.

Gonzalez-Gay MA.(2001) Genetic epidemiology: giant cell arteritis and polymyalgia rheumatica. Arthritis Res 2001;3:154-7.

Gonzalez-Gay M.(2005) The diagnosis and management of patients with giant cell arteritis. J Rheumatol 2005;32:1186-8.

Gonzalez-Gay MA, Barros S, Lopez-Diaz MJ, Garcia-Porrua C, Sanchez-Andrade A, Llorca J. (2005) Giant cell arteritis: disease patterns of clinical presentation in a series of 240 patients. Medicine (Baltimore) 2005;84:269-76.

Gonzalez-Gay MA, Blanco R, Rodriguez-Valverde V, et al.(1998): Permanent visual loss and cerebrovascular accidents in giant cell arteritis: predictors and response to treatment. Arthritis Rheum 1998, 41:1497-1504.

Gonzalez-Gay MA, Garcia-Porrua C, Llorca J, et al.(2001): Biopsynegative giant cell arteritis: clinical spectrum and predictive factors for positive temporal artery biopsy. Semin Arthritis Rheum 2001, 30:249-256.

Gonzalez-Gay MA, Garcia-Porrua C, Llorca J, Gonzalez-Louzao C, Rodriguez-Ledo P. (2001) Biopsy-negative giant cell arteritis: clinical spectrum and predictive factors for positive temporal artery biopsy. Semin Arthritis Rheum 2001;30:249-56.

Gonzalez-Gay MA, Garcia-Porrua C, Llorca J, Hajeer AH, Branas F, Dababneh A, et al.(2000) Visual manifestations of giant cell arteritis: trends and clinical spectrum in 161 patients. Medicine (Baltimore) 2000;79:283-92

Gonzalez-Gay MA, Vazquez-Rodriguez TR, Lopez-Diaz MJ, et al.(2009): Epidemiology of giant cell arteritis and polymyalgia rheumatica Arthritis Rheum 2009, 61:1454-1461.

Henes JC, Müller M, Krieger J, et al.(2008): [18F] FDG-PET/CT as a new and sensitive imaging method for the diagnosis of large vessel vasculitis. Clin Exp Rheumatol 2008, 26(Suppl 49):S47-S52.

Hunder G.G., et al.(1990) - The American College of Reumatology 1990 criteria for the classification of giant cell arteritis, Arteritis Rheum. 1990; 33:1122-28.

Hunder GG, Sheps SG, Allen GL, Joyce JW (1975): Daily and alternate day corticosteroid regimens in treatment of giant cell arteritis: comparison in a prospective study. Ann Intern Med 1975, 82:613-618.

Jianu D.C., Jianu S.N.(2010) - Chapter 8 - Aportul CDI in studiul neuropatiilor optice, in Jianu D.C., Jianu S.N., ed., Ecografia Doppler Color. Interferente oftalmo-neurologice, Mirton, 2010:154-74 
Lee MS, Smith SD, Galor A, Hoffman GS (2006): Antiplatelet and anticoagulant therapy in patients with giant cell arteritis. Arthritis Rheum 2006, 54:3306-3309.

Levine SM, Hellmann DB. (2002) Giant cell arteritis. Curr Opin Rheumatol 2002;14:3-10.

Lopez-Diaz MJ, Llorca J, Gonzalez-Juanatey C, et al.(2008): The erythrocyte sedimentation rate is associated with the development of visual complications in biopsy-proven giant cell arteritis. Semin Arthritis Rheum 2008, 38:116-123.

Mahr AD, Jover JA, Spiera RF, et al.(2007): Adjunctive methotrexate for treatment of giant cell arteritis: an individual patient data metaanalysis. Arthritis Rheum 2007, 56:2789_ 2797.

Mahr A, Saba M, Kambouchner M, et al.(2006): Temporal artery biopsy for diagnosing giant cell arteritis: the longer, the better? Ann Rheum Dis 2006, 65:826-828.

Martínez-Valle F, Solans-Laqué R, Bosch-Gil J, et al.(2010): Aortic involvement in giant cell arteritis. Autoimmun Rev 2010, 9:521-524.

Mazlumzadeh M, Hunder GG, Easley KA, et al.(2006): Treatment of giant cell arteritis using induction therapy with high-dose glucocorticoids: a double-blind, placebocontrolled, randomized prospective clinical trial. Arthritis Rheum 2006, 54:33103318.

Nesher G, Berkun Y, Mates M, et al.(2004): Low-dose aspirin and prevention of cranial ischemic complications in giant cell arteritis. Arthritis Rheum 2004, 50:1332-1337.

Pipitone N, Versari A, Salvarani C (2008): Role of imaging studies in the diagnosis and follow-up of large-vessel vasculitis: an update. Rheumatology (Oxford) 2008, 47:403408.

Rodriguez-Pla A, Bosch-Gil JA, Echevarria-Mayo JE, Rossello-Urgell J, Solans-Laque R, Huguet-Redecilla P, et al. (2004) No detection of parvovirus B19 or herpesvirus DNA in giant cell arteritis. J Clin Virol 2004;31:11-5.

Salvarani C, Cantini F, Hunder GG (2008): Polymyalgia rheumatica and giant-cell arteritis. Lancet 2008, 372:234-245.

Salvarani C, Gabriel SE, O'Fallon WM, Hunder GG. (1995) The incidence of giant cell arteritis in Olmsted County, Minnesota: apparent fluctuations in a cyclic pattern. Ann Intern Med 1995;123:192-4.

Salvarani C, Macchioni P, Zizzi F, Mantovani W, Rossi F, Castri C, et al. (1991) Epidemiologic and immunogenetic aspects of polymyalgia rheumatica and giant cell arteritis in northern Italy. Arthritis Rheum 1991;34:351-6.

Schmidt W.A. (2006) Takayasu and temporal arteritis, in Baumgartner R.W. (ed.): Handbook on Neurovascular Ultrasound. Front.Neurol.Neurosci.Basel, Karger, 2006, 21:96-104.

Schmidt WA, Kraft HE, Vorpahl K, et al.(1997): Color duplex ultrasonography in the diagnosis of temporal arteritis. N Engl J Med 1997, 337:1336-1342.

Taylor-Gjevre R, Vo M, Shukla D, Resch L (2005): Temporal artery biopsy for giant cell arteritis. J Rheumatol 2005, 32:1279-1282.

Tranquart F., Aubert-Urena A.S., Arsene S., Audrierie C., Rossazza C., Pourcelot L. (1997) Echo-Doppler couleur des arteres ciliaires posterieures dans la neuropathie optique ischemique anterieure aigue, J.E.MU. 1997; 18(1):6871.

Weyand CM, Goronzy JJ. (2003) Giant-cell arteritis and polymyalgia rheumatica. Ann Intern Med 2003;139:505-15.

Weyand CM, Tetzlaff N, Bjornsson J, Brack A, Younge B, Goronzy JJ. (1997) Disease patterns and tissue cytokine profiles in giant cell arteritis. Arthritis Rheum 1997;40:19-26. 


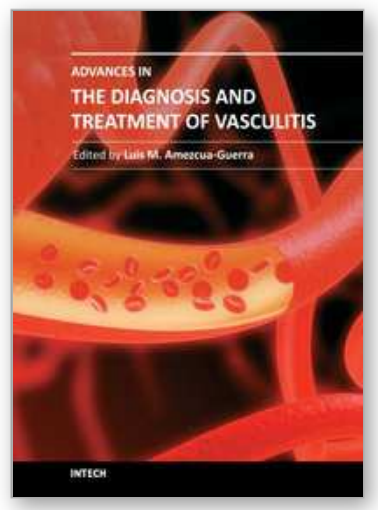

\author{
Advances in the Diagnosis and Treatment of Vasculitis \\ Edited by Dr. Luis M Amezcua-Guerra
}

ISBN 978-953-307-786-4

Hard cover, 366 pages

Publisher InTech

Published online 09, November, 2011

Published in print edition November, 2011

This book represents the culmination of the efforts of a group of outstanding experts in vasculitis from all over the world, who have endeavored to draw themselves into this volume by keeping both the text and the accompanying figures and tables lucid and memorable. The book provides practical information about the screening approach to vasculitis by laboratory analysis, histopathology and advanced image techniques, current standard treatment along with new and more specific interventions including biologic agents, reparative surgery and experimental therapies, as well as miscellaneous issues such as the extra temporal manifestations of "temporal arteritis" or the diffuse alveolar hemorrhage syndrome. The editor and each of the authors invite you to share this journey by one of the most exciting fields of the medicine, the world of Vasculitis.

\title{
How to reference
}

In order to correctly reference this scholarly work, feel free to copy and paste the following:

Jianu Dragoş Cătălin, Jianu Silviana Nina, Petrica Ligia and Şerpe Mircea (2011). Large Giant Cell Arteritis with Eye Involvement, Advances in the Diagnosis and Treatment of Vasculitis, Dr. Luis M Amezcua-Guerra (Ed.), ISBN: 978-953-307-786-4, InTech, Available from: http://www.intechopen.com/books/advances-in-thediagnosis-and-treatment-of-vasculitis/large-giant-cell-arteritis-with-eye-involvement

\section{INTECH}

open science | open minds

\author{
InTech Europe \\ University Campus STeP Ri \\ Slavka Krautzeka 83/A \\ 51000 Rijeka, Croatia \\ Phone: +385 (51) 770447 \\ Fax: +385 (51) 686166 \\ www.intechopen.com
}

\author{
InTech China \\ Unit 405, Office Block, Hotel Equatorial Shanghai \\ No.65, Yan An Road (West), Shanghai, 200040, China \\ 中国上海市延安西路65号上海国际贵都大饭店办公楼 405 单元 \\ Phone: +86-21-62489820 \\ Fax: +86-21-62489821
}


(C) 2011 The Author(s). Licensee IntechOpen. This is an open access article distributed under the terms of the Creative Commons Attribution 3.0 License, which permits unrestricted use, distribution, and reproduction in any medium, provided the original work is properly cited. 